\title{
Identify Common Risk Factor and Clinical Presentation of Myocardial Infarction Among Male and Female Adults in Saudi Arabia
}

\author{
Abdulwahab Alharthi MD ${ }^{1}$, Abdulelah Naif Alenzi MBBS ${ }^{2}$, Waad Hassan Albadrani MBBS, ${ }^{3}$ Abdulaziz \\ Munawir Alsubaie $\mathrm{MBBS}^{4}$,Bander mashhi aldhafeeri MBBS ${ }^{5}$ \\ 1. Ministry of Health, Medina, Saudi Arabia \\ 2. School of Medicine Majmaah University, Riyadh, Saudi Arabia \\ 3. School of Medicine Tibbah University, Medina, Saudi Arabia \\ 4. School of Medicine Majmaah University, Riyadh, Saudi Arabia \\ 5. School of Medicine Majmaah University, Riyadh, Saudi Arabia \\ * E-mail of the corresponding author: ahwila@moh.gov.sa
}

\begin{abstract}
Data on the epidemiology of myocardial infarction (MI) risk factors in Saudi Arabia are limited, particularly in relation to age at MI onset. Therefore, this study aimed at evaluating the prevalence of MI risk factors, as well as MI presentation in the central region of Saudi Arabia.

A cross-sectional survey was conducted between - to - 2019 in a sample of 103 patients with MI. A selfadministered and structured questionnaire assessing the participants' baseline characteristics and MI-related risk factors and symptoms was employed. The analysis included descriptive statistics and chi-square analysis.

There were 55 (53.4\%) male participants and 48 (46.6\%) female participants. Their age ranged 16 to 86 years, with a mean age of $55.5 \pm 14.8$ years. Seventy-one $(68.9 \%)$ patients were above 45 years of age. The most common risk factors for MI were hypertension (58.2\%), diabetes mellitus $(59.2 \%)$, obesity (45.6\%), physical inactivity (36.9\%), smoking (36.9\%), and hypercholesteremia (33.0\%). Patients aged above 45 years of age were more likely to report an established diagnosis of diabetes mellitus, hypertension, and hypercholesteremia (all $P<0.05$ ). the most common reported MI region was inferior wall MI.

MI risk is high among young Saudi adults. Diabetes mellitus, hypertension, and hypercholestermia were significantly more common in older patients with MI. addressing the modifiable risk factors for MI is vital to early prevention of MI.
\end{abstract}

Keywords: myocardial infarction, risk factors, age, Saudi Arabia

DOI: $10.7176 / \mathrm{JHMN} / 69-11$

Publication date: December $31^{\text {st }} 2019$

\section{Introduction}

Globally, acute myocardial infarction (MI) is one of the major causes of morbidity and mortality. The burden is more significant when the patients are young as they are in the most flourishing stages of their life and have the potential to contribute to their family and society (1-7). Though noticeably limited, observational reports suggest that acute MI occurs in around $2 \%$ to $10 \%$ of young adults (8).

Particular risk factors have been found to be commonly associated with MI in this age group, including male gender, smoking, and hyperlipidemia (2,3,9-11). Family history of ischemic heart disease and hypertension have also been reported as common risk factors (12).

In a recent prospective cohort study, the classical presentation of acute MI in adult patients, the chest pain is the main symptom and represents of $91.6 \%$ of cases and the proportion of young adults (35 years or younger) with acute coronary syndrome represented $195(0.7 \%)$ of a total population of 28, 778 patients (13). These findings emphasize the recurrent question about the need for and timing of coronary angiography in young patients who have lower probability of MI given their fewer coronary risk factors (14). This has led to a trending belief that the global risk of cardiovascular diseases in this population may be underestimated (15).

Epidemiological studies of MI presentation and risk factors in this population are lacking. A retrospective study conducted by Al-Khadra (2003) included 65 patients (23.1\% Saudis) supported the aforementioned common risk factors in addition to diabetes $(30.8 \%)$. The vast majority of cases $(92.3 \%)$ were MI with ST elevation and the anterior wall was the most common anatomical location of the MI (16). The present study aimed to assess the clinical presentation of and to evaluate the risk factors for acute MI in Saudi young adults younger than 45 years old. 


\section{Methods}

"This is a cross-sectional study of MI risk factors and clinical presentation in male and female patients under 45 years in Riyadh region, Saudi Arabia. The study was conducted between - to - 2019, using a structured and selfadministered questionnaire was randomly distributed among a sample of 103 MI patients. Participation was entirely anonymous and voluntary, and participants were asked to provide informed written consent before participation. The study was approved by the Ethics Committee of Majmaah University.

The questionnaire incorporated questions on the participants' baseline characteristics (sex, age, marital status, and employment status). In addition, MI risk factors, such as diabetes mellitus (DM), hypertension (HTN), smoking, physical inactivity, etc. were assessed using self-reported multiple-choice questions. Participants were also asked about the region of MI and some clinical data, such as electrocardiogram (ECG) findings and enzymatic changes. Family history of coronary artery syndrome (CAD) was also assessed.

The mean and standard deviation was calculated for continuous variables. Categorical variables were presented as frequencies and percentages. Data were analyzed using the Statistical Package of Social Sciences (SPSS) Version 20 (SPSS, IBM Corp., Armonk, NY, USA).

\section{Results}

There were 55 (53.4\%) male participants and 48 (46.6\%) female participants aged 16 to 86 years, with a mean age of $55.5 \pm 14.8$ years. A total of $70(68.0 \%)$ participants were married, $17(16.5 \%)$ were Divorced/widowed (widower), and 16 (15.5\%) were single. Regarding employment status, 64 (62.1\%) were not employed, $24(23.3 \%)$ were employed, $11(10.7 \%)$ were retired, and 4 (3.9\%) were student (Table 1).

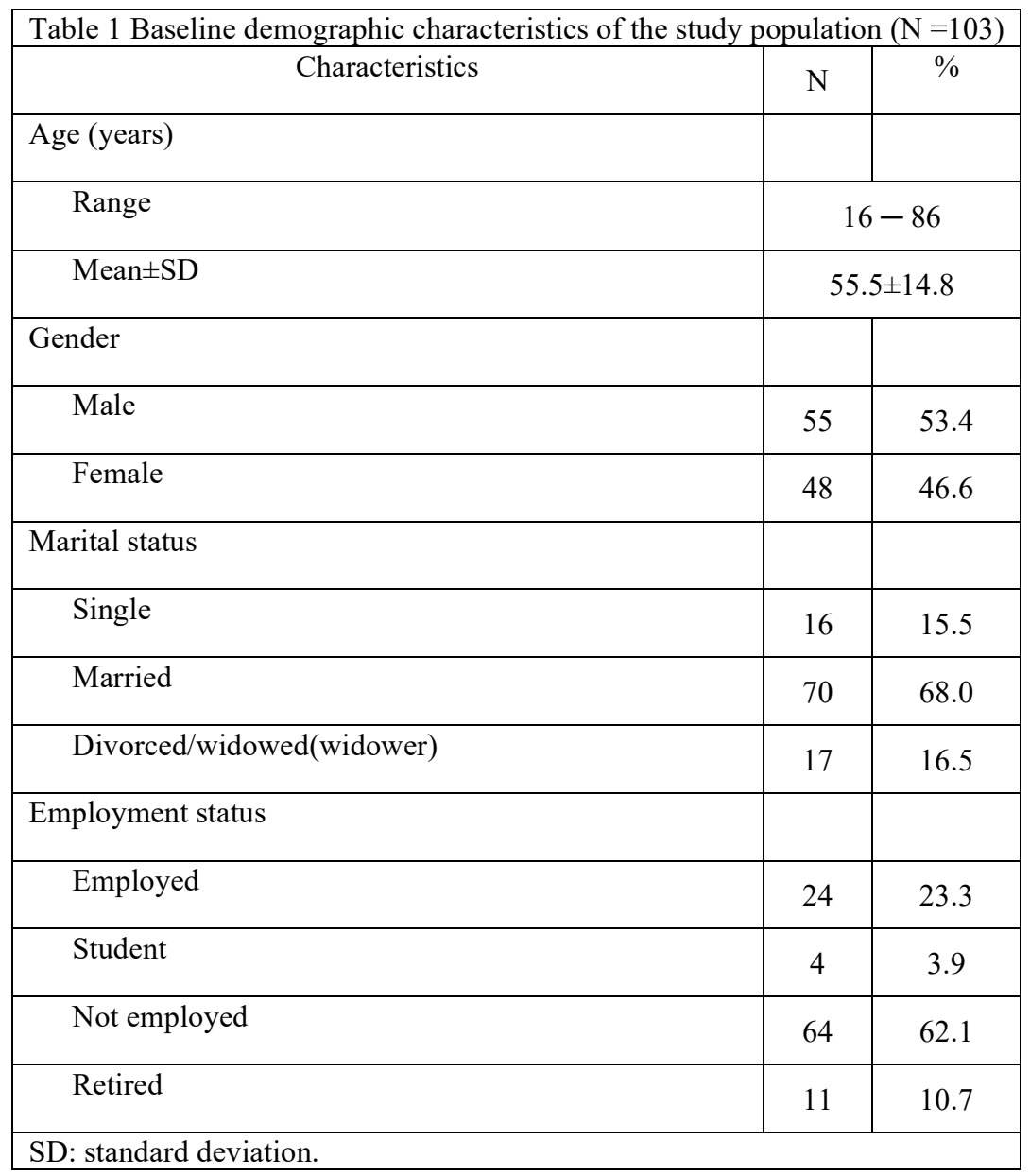

Table 2 shows the distribution of risk factors in patients with MI. More than two-thirds (68.9\%) were above 45 years of age. Hypertension was observed in $58.2 \%$ of the participants, diabetes mellitus in $59.2 \%$, obesity in $45.6 \%$, 
physical inactivity in $36.9 \%$, smoking in $36.9 \%$, and hypercholesteremia in $33.0 \%$. A combination of these risk factors was self-reported by some patients and is shown in Table 2.

\begin{tabular}{|l|c|c|}
\hline \multicolumn{1}{|c|}{ Table 2 Distribution of risk factors in patients with MI } & N & $\%$ \\
\hline Age at MI (years) & 32 & 31.1 \\
\hline 45 or below & 71 & 68.9 \\
\hline Above 45 & 61 & 59.2 \\
\hline DM & 60 & 58.2 \\
\hline HTN & 47 & 45.6 \\
\hline Obesity & 38 & 36.9 \\
\hline Physical inactivity & 38 & 36.9 \\
\hline Smoking & 34 & 33.0 \\
\hline Hypercholesteremia & 14 & 13.6 \\
\hline Family history of CAD & 23 & 22.3 \\
\hline HTN + DM + obesity & 15 & 14.6 \\
\hline DM + Hypercholesteremia + obesity & 10 & 9.7 \\
\hline DM + physical inactivity + obesity & 8 & 7.8 \\
\hline HTN + DM + Hypercholesteremia + physical inactivity & 6.8 \\
\hline physical inactivity + smoking & 7 & \\
\hline MI: myocardial infarction, HTN: hypertension, DM: diabetes mellitus, CAD: coronary artery disease. & & \\
\hline & 38 \\
\hline
\end{tabular}

Various risk factors for MI were compared between participants in different age groups. The analysis showed that patients who had MI after 45 years of age were more likely to self-report having DM, HTN, and hypercholesteremia (all $P<0.05$ ). No significant difference was found between different age groups and other risk factors for MI (Table 3).

\begin{tabular}{|l|c|c|c|}
\hline \multirow{2}{*}{ Risk factor } & \multicolumn{2}{|c|}{ Age at MI } & \\
\cline { 2 - 4 } & 45 or below $(\mathrm{N}=32)$ & Above 45 (N =71) & $P$ \\
\hline DM & 43.8 & 70.4 & 0.015 \\
\hline HTN & 40.6 & 64.8 & 0.031 \\
\hline Obesity & 43.8 & 43.7 & 1.000 \\
\hline Hypercholesteremia & 21.9 & 43.7 & 0.047 \\
\hline Smoking & 43.8 & 25.4 & 0.070 \\
\hline Physical inactivity & 46.9 & 38.0 & 0.516 \\
\hline Family history of CAD & 3.1 & 15.5 & 0.098 \\
\hline MI: myocardial infarction, HTN: hypertension, DM: diabetes mellitus, CAD: coronary artery disease. \\
\hline
\end{tabular}


Table 4 shows MI symptoms as reported by the study subjects. Palpitation was more likely to be reported by older patients than youngers $(P<0.01)$. The analysis detected no other significant differences in MI symptoms among patients from different age groups (Table)

Table 4 Distribution of MI symptoms, by age at MI onset

\begin{tabular}{|c|c|c|c|c|}
\hline \multirow{2}{*}{ Symptom } & & \multicolumn{2}{|c|}{ Age at MI } & \multirow[b]{2}{*}{$P$} \\
\hline & $\begin{array}{c}\text { Total }(\mathrm{N} \\
=103)\end{array}$ & $\begin{array}{c}45 \text { or below }(\mathrm{N} \\
=32)\end{array}$ & $\begin{array}{c}\text { Above } 45(\mathrm{~N} \\
=71)\end{array}$ & \\
\hline Chest pain & 45.6 & 53.1 & 42.3 & 0.393 \\
\hline $\begin{array}{l}\text { Chest pain radiating to neck, shoulders, or } \\
\text { arms }\end{array}$ & 46.6 & 40.6 & 49.3 & 0.523 \\
\hline Palpitation & 36.9 & 15.6 & 46.5 & 0.004 \\
\hline Sweating & 43.7 & 40.6 & 45.1 & 0.830 \\
\hline Fatigue & 31.1 & 34.4 & 29.6 & 0.651 \\
\hline Nausea & 35.9 & 37.5 & 35.2 & 0.828 \\
\hline Shortness of breath & 53.4 & 50.0 & 54.9 & 0.674 \\
\hline Vomiting & 18.4 & 15.6 & 19.7 & 0.786 \\
\hline
\end{tabular}

Inferior MI was reported by $18.4 \%$ of the participants, anterior MI by $13.6 \%$, and lateral MI by $10.7 \%$. MI involving more than one side was reported by $13.6 \%$. ECG and enzymatic changes were reported by $43.7 \%$ and $49.5 \%$, respectively (Table 3 ).

\begin{tabular}{|c|c|c|}
\hline Characteristics & $\mathrm{N}$ & $\%$ \\
\hline \multicolumn{3}{|l|}{ Side } \\
\hline Inferior & 19 & 18.4 \\
\hline Lateral & 11 & 10.7 \\
\hline Anterior & 14 & 13.6 \\
\hline more than one side & 14 & 13.6 \\
\hline Not known MI & 45 & 43.7 \\
\hline ECG changes & 51 & 49.5 \\
\hline Enzymatic changes & 55 & 53.4 \\
\hline
\end{tabular}

\section{Discussion}

The present retrospective investigation was performed on a sample of MI patients in central region of Saudi Arabia. The most common risk factors were age above 45 years, diabetes mellitus, hypertension, obesity, physical inactivity, and smoking. These traditional risk factors for MI affected more than one-third of the surveyed patients, a finding similar to what has been shown by Framingham Heart study (17) the INTERHEART study (18), and several previous studies (19-21). The study identified that $6.8 \%$ to $22.3 \%$ of the subjects represented a high risk group, who had three of more risk factors for MI. Notably, as much as $23.3 \%$ were obese and reported an established diagnosis of diabetes mellitus and hypertension. The main aim of this study was to compare MI presentation and risk factors between patients under 45 years of age and those aged 45 years and above. Our findings suggested that older patients significantly suffered from diabetes, hypertension, and hypercholesteremia more than did younger patients $(\mathrm{P}<0.05)$. Age was of a weak effect on MI presentation in this survey, as only one symptom (palpitation) was more likely to be reported by older subjects.

While age is a well-known risk factor for MI, we found a considerable proportion of young adults $(<45$ years $)$ suffering from MI. Previous research has pointed to the increasing incidence of MI among people younger than 45 years (20). These findings are concerning, as having MI at such age can have negative impact on social, psychological (22), and productivity of the patients (23), in addition to the quality of life of patients and their relatives (24) and related economic consequences (25).

Although insignificant, the analysis showed that patients below 45 years of age reported obesity, smoking, and physical inactivity more commonly than did older patients. All of these risk factors for MI are modifiable, therefore, early identification of them and prevention are vital strategies to MI prevention (26).

Inferior wall was the most common side affected among the surveyed population (18.4\%). Inferior wall MI occurs 
from occlusion of the coronary artery that results in decreased perfusion to the inferior myocardium. MI involving the inferior wall occurs in approximately $40 \%$ of all MIs and it is associated with a better prognosis than MIs in other regions, such as anterior MI (27-29). However, these findings were self-reported and may lack accuracy, which is a limitation of the study. Other limitations include the relatively small sample size and the use of a selfreported questionnaire.

\section{Conclusion}

We conclude that MI risk is high among young Saudi adults. DM, HTN, and hypercholesteremia were significantly more common in older patients with MI. A considerable proportion of young patients ( $<45$ years) had modifiable MI risk factors, such as obesity, physical inactivity, and smoking. Therefore, addressing the modifiable risk factors for MI is vital to early prevention of MI.

\section{References}

1. Zimmerman FH, Cameron A, Fisher LD, Ng G. Myocardial infarction in young adults: angiographic characterization, risk factors and prognosis (Coronary Artery Surgery Study Registry). J Am Coll Cardiol [Internet]. 1995 Sep;26(3):654-61. Available from: http://www.ncbi.nlm.nih.gov/pubmed/7642855

2. Chan MY, Woo KS, Wong HB, Chia BL, Sutandar A, Tan HC. Antecedent risk factors and their control in young patients with a first myocardial infarction. Singapore Med J [Internet]. 2006 Jan;47(1):27-30. Available from: http://www.ncbi.nlm.nih.gov/pubmed/16397717

3. Tambyah PA, Lim YT, Choo MH. Premature myocardial infarction in Singapore--risk factor analysis and clinical features. Singapore Med J [Internet]. 1996 Feb;37(1):31-3. Available from: http://www.ncbi.nlm.nih.gov/pubmed/8783909

4. Colkesen AY, Acil T, Demircan S, Sezgin AT, Muderrisoglu H. Coronary lesion type, location, and characteristics of acute ST elevation myocardial infarction in young adults under 35 years of age. Coron Artery Dis [Internet]. 2008 Aug;19(5):345-7. Available from: http://www.ncbi.nlm.nih.gov/pubmed/18607172

5. Chua S-K, Hung H-F, Shyu K-G, Cheng J-J, Chiu C-Z, Chang C-M, et al. Acute ST-elevation myocardial infarction in young patients: 15 years of experience in a single center. Clin Cardiol [Internet]. 2010 Mar;33(3):140-8. Available from: http://www.ncbi.nlm.nih.gov/pubmed/20235218

6. Ismail J, Jafar TH, Jafary FH, White F, Faruqui AM, Chaturvedi N. Risk factors for non-fatal myocardial infarction in young South Asian adults. Heart [Internet]. 2004 Mar;90(3):259-63. Available from: http://www.ncbi.nlm.nih.gov/pubmed/14966040

7. Choudhury L, Marsh JD. Myocardial infarction in young patients. Am J Med [Internet]. 1999 Sep;107(3):254-61. Available from: http://www.ncbi.nlm.nih.gov/pubmed/10492319

8. Wong CP, Loh SY, Loh KK, Ong PJL, Foo D, Ho HH. Acute myocardial infarction: Clinical features and outcomes in young adults in Singapore. World J Cardiol [Internet]. 2012 Jun 26;4(6):206-10. Available from: http://www.ncbi.nlm.nih.gov/pubmed/22761974

9. Milionis HJ, Kalantzi KJ, Papathanasiou AJ, Kosovitsas AA, Doumas MT, Goudevenos JA. Metabolic syndrome and risk of acute coronary syndromes in patients younger than 45 years of age. Coron Artery Dis [Internet]. 2007 Jun;18(4):247-52. Available from: http://www.ncbi.nlm.nih.gov/pubmed/17496487

10. Kanitz MG, Giovannucci SJ, Jones JS, Mott M. Myocardial infarction in young adults: risk factors and clinical features. J Emerg Med [Internet]. 14(2):139-45. Available from: http://www.ncbi.nlm.nih.gov/pubmed/8740743

11. Weinberger I, Rotenberg Z, Fuchs J, Sagy A, Friedmann J, Agmon J. Myocardial infarction in young adults under 30 years: risk factors and clinical course. Clin Cardiol [Internet]. 1987 Jan;10(1):9-15. Available from: http://www.ncbi.nlm.nih.gov/pubmed/3815921

12. Kanitz MG, Giovannucci SJ, Jones JS, Mott M. Myocardial infarction in young adults: risk factors and clinical features. J Emerg Med [Internet]. 1996 Mar;14(2):139-45. Available from: http://www.ncbi.nlm.nih.gov/pubmed/8740743

13. Schoenenberger AW, Radovanovic D, Stauffer J-C, Windecker S, Urban P, Niedermaier G, et al. Acute coronary syndromes in young patients: presentation, treatment and outcome. Int J Cardiol [Internet]. 2011 May 5;148(3):300-4. Available from: http://www.ncbi.nlm.nih.gov/pubmed/19942306

14. Pellaton C, Monney P, Ludman AJ, Schwitter J, Eeckhout E, Hugli O, et al. Clinical features of myocardial infarction and myocarditis in young adults: a retrospective study. BMJ Open [Internet]. 2012;2(6). Available from: http://www.ncbi.nlm.nih.gov/pubmed/23204138

15. Zarich S, Luciano C, Hulford J, Abdullah A. Prevalence of metabolic syndrome in young patients with acute MI: does the Framingham Risk Score underestimate cardiovascular risk in this population? Diabetes Vasc Dis Res [Internet]. $2006 \quad$ Sep;3(2):103-7. Available from: 
http://www.ncbi.nlm.nih.gov/pubmed/17058630

16. Al-Khadra AH. Clinical profile of young patients with acute myocardial infarction in Saudi Arabia. Int J Cardiol [Internet]. $2003 \quad$ Sep;91(1):9-13. Available from: https://linkinghub.elsevier.com/retrieve/pii/S016752730200579X

17. Mahmood SS, Levy D, Vasan RS, Wang TJ. The Framingham Heart Study and the epidemiology of cardiovascular disease: a historical perspective. Lancet (London, England) [Internet]. 2014 Mar 15;383(9921):999-1008. Available from: http://www.ncbi.nlm.nih.gov/pubmed/24084292

18. Anand SS, Islam S, Rosengren A, Franzosi MG, Steyn K, Yusufali AH, et al. Risk factors for myocardial infarction in women and men: insights from the INTERHEART study. Eur Heart J [Internet]. 2008 Apr;29(7):932-40. Available from: http://www.ncbi.nlm.nih.gov/pubmed/18334475

19. Kalaf H, AlMesned A, Soomro T, Lasheen W, Ewid M, Al-Mohaimeed AA. Cardiovascular disease risk profile among young Saudi women of Al-Qassim, Saudi Arabia: A cross-sectional study. Int J Health Sci (Qassim) [Internet]. $2016 \quad$ Jan;10(1):29-37. Available from: http://www.ncbi.nlm.nih.gov/pubmed/27004055

20. Bahall M, Seemungal T, Legall G. Risk factors for first-time acute myocardial infarction patients in Trinidad. BMC Public Health [Internet]. 2018;18(1):161. Available from: http://www.ncbi.nlm.nih.gov/pubmed/29351744

21. Zodpey SP, Shrikhande SN, Negandhi HN, Ughade SN, Joshi PP. Risk factors for acute myocardial infarction in central India: a case-control study. Indian J Community Med [Internet]. 40(1):19-26. Available from: http://www.ncbi.nlm.nih.gov/pubmed/25657508

22. Frasure-Smith N, Lespérance F. Depression and other psychological risks following myocardial infarction. Arch Gen Psychiatry [Internet]. 2003 Jun;60(6):627-36. Available from: http://www.ncbi.nlm.nih.gov/pubmed/12796226

23. Bucholz EM, Normand S-LT, Wang Y, Ma S, Lin H, Krumholz HM. Life Expectancy and Years of Potential Life Lost After Acute Myocardial Infarction by Sex and Race: A Cohort-Based Study of Medicare Beneficiaries. J Am Coll Cardiol [Internet]. 2015 Aug 11;66(6):645-55. Available from: http://www.ncbi.nlm.nih.gov/pubmed/26248991

24. Garcia RP, Budó M de LD, Simon BS, Wünsch S, Oliveira SG, Barbosa M da S. [Family experiences post-acute myocardial infarction]. Rev Gauch Enferm [Internet]. 2013 Sep;34(3):171-8. Available from: http://www.ncbi.nlm.nih.gov/pubmed/24344600

25. Kawano H, Soejima H, Kojima S, Kitagawa A, Ogawa H, Japanese Acute Coronary Syndrome Study (JACSS) Investigators. Sex differences of risk factors for acute myocardial infarction in Japanese patients. Circ J [Internet]. $2006 \quad$ May;70(5):513-7. Available from: http://www.ncbi.nlm.nih.gov/pubmed/16636482

26. El-Menyar A, Zubaid M, Shehab A, Bulbanat B, Albustani N, Alenezi F, et al. Prevalence and impact of cardiovascular risk factors among patients presenting with acute coronary syndrome in the middle East. Clin Cardiol [Internet]. 2011 Jan;34(1):51-8. Available from: http://www.ncbi.nlm.nih.gov/pubmed/21259279

27. Balasubramanian K, Ramachandran B, Subramanian A, Balamurugesan K. Combined ST Elevation in a Case of Acute Myocardial Infarction: How to Identify the Infarct-related Artery? Int J Appl basic Med Res [Internet]. 8(3):184-6. Available from: http://www.ncbi.nlm.nih.gov/pubmed/30123751

28. Lévy S. Bundle branch blocks and/or hemiblocks complicating acute myocardial ischemia or infarction. J Interv Card Electrophysiol [Internet]. 2018 Aug;52(3):287-92. Available from: http://www.ncbi.nlm.nih.gov/pubmed/30136134

29. Aydin F, Turgay Yildirim O, Dagtekin E, Huseyinoglu Aydin A, Aksit E. Acute Inferior Myocardial Infarction Caused by Lightning Strike. Prehosp Disaster Med [Internet]. 2018 Dec;33(6):658-9. Available from: http://www.ncbi.nlm.nih.gov/pubmed/30156178 